\title{
VERTENTES TEÓRIO-METODOLÓGICAS NORTEADORAS DOS TRABALHOS DE CONCLUSÃO DE CURSO DE PEDAGOGIA DA FURB NO PERÍODO DE 2001 A 2006
}

\author{
Maria Aparecida Porto Lucas \\ Rita Buzzi Rausch
}

\section{RESUMO}

Analisamos as vertentes teórico-metodológicas que nortearam os TCCs da Pedagogia da FURB no período de 2001 a 2006. Fizemos uma análise documental dos 321 trabalhos realizados. Constatamos que todos os trabalhos desenvolvidos voltaram-se à área da Educação. Quanto às subáreas, predominaram: educação pré-escolar, psicologia educacional, educação especial e sociologia da educação. Os teóricos mais utilizados foram: Vygotsky, Piaget, Kramer, Freire, Áries, Wallon e Ferreiro. Frente às subáreas, sugerimos que as futuras pesquisas contemplem investigações nos campos não ou poucos explorados. Entendemos que os clássicos são importantes e precisam ser utilizados, entretanto, sentimos falta, em alguns trabalhos, de autores mais específicos ao objeto em estudo. As pesquisas, em sua maioria, delinearam-se na abordagem qualitativa, destacando-se o uso de dados quantitativos em alguns trabalhos. Quanto aos tipos de pesquisa predominaram a pesquisa exploratória, participante e estudo de caso. Consideramos que estes tipos de pesquisa estão relacionados ao processo de iniciação à pesquisa. Os instrumentos de coleta de dados, os mais utilizados foram o questionário, precedido da entrevista e da observação. Cabe ressaltar, que muitos acadêmicos utilizaram mais de um instrumento, o que possivelmente possibilitou compreender o objeto sob vários aspectos.

\section{PALAVRAS-CHAVE}

Pedagogia; Iniciação à pesquisa; Trabalho de conclusão de curso; Metodologia da pesquisa

\section{METHODOLOGICAL AND THEORETICAL GUIDELINES IN THE END OF TERM PAPERS OF THE PEDAGOGY COURSE AT FURB UNIVERSITY FROM 2001 TO 2006}

\begin{abstract}
A documental analysis has been made on the methodological and theoretical guidelines in the end of term papers of the Pedagogy Course at FURB University in 321 works from 2001 to 2006. It has been noticed that all the developed papers focused the educational area. As for the sub areas, the predominant ones were: education in Pre School, educational psychology, special education and educational sociology. The most used theoretical authors were: Vygotsky, Piaget, Kramer, Freire, Aries, Wallon and Ferreiro. For the sub areas, it has been suggested that the future researches should include investigations on less or not focused studied fields. The importance of classic objects of research has been understood and those must be tackled. However, in some works there is an absence of more specific authors on the studied object. Most researches have been developed on the qualitative approach and some have used quantitative data. In relation to the research types, the predominant ones were the exploratory, participant and case study types. It has been considered that such kinds are related to the process of initiation to research. The most used instruments for data collection were a questionnaire preceded by interview and observation. Several research students have used more than one instrument, which possibly led to a comprehension of the subject under a variety of aspects.
\end{abstract}

\section{KEYWORDS}

Pedagogy; Initiation to research; End of term paper; Research methodology 


\section{INTRODUÇÃO}

A pesquisa ainda não figura como parte integrante nos cursos de formação de professores (LÜDKE, 2004). Muitos profissionais concluem sua licenciatura sem nunca ter vivenciado ou participado de um processo de pesquisa. Só mais recentemente, as políticas públicas voltadas à formação inicial de professores, têm dado uma atenção mais específica à pesquisa. Destacamos a proposta de Diretrizes para a Formação Inicial de Professores da Educação Básica em Cursos de Nível Superior (BRASIL, 2001), elaborada pelo Conselho Nacional de Educação que defende a pesquisa como elemento essencial na formação do profissional da educação. Ressalta a importância de uma postura reflexiva docente; o domínio de procedimentos de investigação científica pelo professor; a sistematização de informações; a análise de dados; o levantamento de hipóteses e verificação, no qual deverá produzir e socializar conhecimentos pedagógicos.

Coerente com tais diretrizes, algumas instituições de Educação Superior vêm incentivando a participação dos licenciandos em Programas de Iniciação Científica e adaptando o currículo da formação inicial de professores, incluindo, além de metodologias investigativas nas diferentes disciplinas que compõem a matriz curricular do curso, atividades diretamente voltadas à Iniciação à Pesquisa. O Trabalho de Conclusão de Curso surge na formação inicial buscando contribuir com essa formação.

Foi com a intenção de incluir na formação inicial uma proposta que contemple a dimensão reflexiva e científica que implementamos, no currículo do curso de Pedagogia, na Universidade Regional de Blumenau - FURB, o Trabalho de Conclusão de Curso que busca versar sobre um tema referente à educação, voltando-se a um processo de Iniciação à Pesquisa. A reflexão sobre a realidade escolar observada, sustentada na fundamentação teórica refletida no curso, gera problematizações de pesquisa entendidos como formas de Trabalho de Conclusão de Curso.

Desta forma, o curso de Pedagogia da FURB busca a promoção da reflexividade docente, além de outras atividades, também por meio da pesquisa. Nesse sentido, o Trabalho de Conclusão de Curso pretende contribuir para que o acadêmico-professor pense acerca de sua profissão com o intuito de assumir, no dia-a-dia da docência, uma prática reflexiva e investigativa, ou seja, uma disposição e competência para a análise individual e coletiva da 
sua atuação, para um olhar introspectivo, para pensar, decidir, agir, tirando conclusões e dando novos encaminhamentos à sua ação docente.

O TCC aconteceu, no período de 2001 a 2006, na última fase do curso de graduação, no qual os acadêmicos em duplas ou individualmente, selecionaram um objeto de investigação e convidavam um professor da área para orientá-los. Além dessa orientação entre acadêmico(s) e orientador, era realizada, também, uma orientação coletiva pela coordenação do TCC do curso acerca dos princípios e métodos da pesquisa.

Nesta trajetória de seis anos de implantação do Trabalho de Conclusão de Curso no Curso de Pedagogia, algumas indagações vêm, há algum tempo, invadindo nosso pensamento. Dentre elas destacamos: Quais são as vertentes teóricas e metodológicas que sustentam as pesquisas dos acadêmicos da Pedagogia? Quais são as temáticas e ou áreas do conhecimento que predominam na escolha do objeto de pesquisa dos acadêmicos? Os objetos de pesquisa escolhidos apresentam relação com a habilitação profissional do curso e com a prática docente?

Frente a tais indagações desafiamo-nos, nesta pesquisa, a analisar as vertentes teórico-metodológicas norteadoras dos TCCs da Pedagogia da FURB realizados no período de 2001 a 2006. Para alcançar tal objetivo, propomos mapear os trabalhos de conclusão de curso da Pedagogia da FURB realizados neste período e identificar as subáreas de concentração, perspectivas teóricas, tipos de pesquisa e instrumento de coleta de dados empregados.

\section{O TCC NO CURSO DE PEDAGOGIA DA FURB}

O Curso de Pedagogia da FURB, desde a sua implantação em 1968, vem passando por várias reformulações curriculares numa tentativa de adequação às novas concepções de formação de professores no ensino superior e à legislação vigente. De acordo com o Projeto Político Pedagógico da FURB (2004), o curso de graduação de Pedagogia definiu como objetivo central formar profissionais com base teórico-prática que permita a reflexão crítica, a autonomia intelectual e a atuação profissional comprometida com um processo educativo emancipador. 
Com base nesse objetivo, busca desenvolver uma formação em que o profissional/pedagogo tenha como desafio constante, a investigação, o aprender contínuo, a pesquisa, o investir na própria formação e tenha como meta, também, a criação de uma atitude de compromisso, sendo co-responsável pela sua formação, criando e recriando a sua prática docente fundamentada em um processo crítico reflexivo.

Dessa forma, hoje, o curso apresenta uma proposta de formação delineada em uma concepção crítico-reflexiva que defende uma prática viva, construída a partir e para a realidade do contexto educacional. A proposta busca articular as dimensões técnicas, humanas e sociopolíticas da educação fundamentadas em teorias que sustentam uma prática inovadora capaz de atender as necessidades reais de nossa sociedade e contribuir com a construção de um ser humano cada vez mais emancipado (FURB, 2004).

Buscando operacionalizar tal formação, dentre outras ressignificações no curso, incluímos na matriz curricular de Pedagogia, já em 1998, o TCC, cujo objetivo é “vivenciar o processo de iniciação científica a partir dos princípios básicos da pesquisa, desenvolvendo no acadêmico uma atitude investigativa/reflexiva como condição da docência” (FURB, 2004, p.28). Assim, esta passou a ser uma atividade obrigatória na integralização curricular do Curso de Pedagogia. É um trabalho que deve versar sobre um tema/problema referente à educação, preferencialmente, relacionado à prática pedagógica, voltando-se a um processo de iniciação à pesquisa.

Portanto, passa a ser um movimento que ensina os acadêmicos a pesquisar fazendo pesquisa, considerando o gradativo avanço defendido por Beillerot (2001) entre estar em pesquisa, fazer pesquisa e ser pesquisador. Assim, esse processo busca avançar de um estágio de "estar em pesquisa”, em que o acadêmico reflete sobre seus problemas, sobre dificuldades encontradas, sobre sua prática profissional; para "fazer pesquisa”, em que o próprio acadêmico dá o tom, a cor e a direção de um trabalho científico, com a orientação de um professor mais experiente, vivenciado cada etapa desse processo, para quem sabe, um dia tornar-se um "pesquisador”. Entendemos que para ser um professor-pesquisador não basta “estar em pesquisa”, é preciso a experiência de fazer pesquisa por meio de um referencial teórico e procedimento metodológico que dê respaldo a essa atividade. Não que toda a pesquisa que o professor realiza no dia-a-dia de sua profissão tenha que ter a rigorosidade e sistematização de uma pesquisa científica, mas compreende-se que o conhecimento desse 
processo virá a contribuir com cuidados imprescindíveis a sua realização, independente de qual forma seja. Compreendemos que o "fazer pesquisa” permite ao acadêmico "estar em pesquisa” de maneira mais crítica e reflexiva.

Embora o TCC tenha sido incluído na matriz curricular do curso em 1998, por acontecer na última fase do curso, e ter a duração de quatro anos, a primeira turma de acadêmicos a realizá-lo ocorreu em 2001. A regulamentação dessa atividade foi definida pelo colegiado do curso de Pedagogia e aprovada pelos conselhos internos da instituição, cuja sistematização consta na Resolução FURB no 29, de 27 de junho de 2001. Cabe destacar que em 2007 foi aprovado nos conselhos internos um novo regulamento, que dentre outras reformulações, subdivide esta atividade em TCC1 e TCC2, acontecendo nas duas últimas fases do curso, em paralelo com outras disciplinas. Esta alteração foi solicitada devido ao pouco tempo compreendido pelos professores e alunos, que é de um semestre, para o desenvolvimento de uma pesquisa científica.

Nessa atividade, os acadêmicos que cursavam o penúltimo semestre do curso, selecionaram um objeto de investigação, em duplas ou individualmente, e convidaram um professor da área para orientá-los. Isso já foi realizado na sétima fase para que o acadêmico mantivesse um contato inicial com seu orientador definindo previamente autores, obras, desenho metodológico da pesquisa e para que o professor reservasse carga horária no semestre posterior para a orientação. É importante destacar que o professor escolhido pelo acadêmico não precisava ser necessariamente do curso de Pedagogia. De acordo com o regulamento próprio da atividade, o critério estabelecido era que o orientador fosse professor da FURB e tivesse a titulação de, no mínimo, mestre. Frente a isto, os acadêmicos, além de professores do curso de Pedagogia, convidavam professores dos cursos de Psicologia, História, Educação Física, Biologia, Filosofia, Letras, Artes para orientá-los, estreitando a relação entre objeto a ser investigado e a formação específica do professor orientador.

A matriz curricular do curso, no período de 2001 a 2006, contemplava no último semestre, somente a atividade de TCC. Portanto, teoricamente, os alunos se envolviam integralmente à realização do TCC. Nessa fase desenvolveram formalmente essa atividade em parceria com o professor orientador, tendo encontros semanais na instituição, cujos dias e horários eram definidos por eles a partir de suas disponibilidades. Ressaltamos que o professor orientador disponibilizava para orientação de cada pesquisa, no mínimo 18h/a no 
semestre, que era a carga horária remunerada para tal atividade. Cabe destacar, aqui, ainda que cada professor orientou, em cada semestre, no máximo, quatro pesquisas de TCC.

Compreendemos que o orientador exerce um papel fundamental no processo de iniciação à pesquisa. É ele que, como profissional mais experiente, orienta cada etapa da pesquisa, o planejamento, a execução e a sistematização. Entretanto, isso não significa que ele deva fazer a pesquisa pelos seus orientandos. A diretriz estabelecida pelo colegiado de Pedagogia na universidade é de que os alunos devam sentir-se orientados e não mandados, para que possam crescer e compreender o que estão fazendo, o porquê e como estão desenvolvendo a pesquisa. Nos encontros de orientação deve existir uma relação dialógica. A relação que é estabelecida nesse processo inicial é fundamental para que os acadêmicos continuem fazendo pesquisa após a conclusão do curso, sem ao contrário, afastá-los dessa atividade. Conforme Ferreira Sobrinho (1997) o papel do orientador não deve ser o papel de pai, de tutor, de protetor, de advogado de defesa, de analista, como também não deve ser de feitor, de carrasco, de senhor dos escravos ou de coisa parecida. Ele é acima de tudo um educador, e deve estabelecer, portanto, com seu orientando, uma relação educativa, no plano da elaboração científica, entre pesquisadores. Assim, o processo de orientação consiste numa leitura e discussão conjuntas, num embate de idéias, de apresentação de sugestões e críticas, no qual não acontecem imposições, mas, convencimentos, esclarecimentos, prevenções acerca do conteúdo e do método da pesquisa.

Além da orientação entre acadêmico(s) e orientador, era realizada, também, uma orientação coletiva pela coordenação do TCC acerca dos princípios e métodos da pesquisa. Durante o semestre foram realizados encontros coletivos entre coordenação e acadêmicos matriculados na atividade para estudos do regulamento específico, orientações quanto à estrutura do projeto de pesquisa e relatório final, estudos sobre as etapas do planejamento, execução e sistematização da pesquisa, definições de cronogramas e procedimentos, esclarecimentos acerca da avaliação da atividade, seleção de professores avaliadores para cada pesquisa específica. Em síntese, eram momentos em que os acadêmicos recebiam da coordenação do TCC esclarecimentos administrativos da atividade, bem como orientações de aspectos metodológicos gerais de trabalhos de cunho científico.

Aconteciam, também, encontros entre a coordenação e os professores orientadores de TCC de cada semestre letivo em forma de grupo de estudos. Juntos, ajudavam-se mutuamente em suas possibilidades no processo de orientar e trocavam sugestões acerca de 
seus avanços. É o momento que aproveitavam, também, para sanar suas dúvidas junto à coordenação quanto aos aspectos legais e administrativos da atividade. A atividade de orientar passou a ser um processo rico de aprendizagem também para os professores de Pedagogia pela pouca vivência e experiência em pesquisa. Cabe destacar que nesses encontros houve uma estreita parceria com os professores doutores que atuavam no Mestrado em Educação da instituição. A partir das necessidades apontadas pelo grupo de professores orientadores, esses profissionais eram convidados para aprofundar questões que se faziam necessárias, como por exemplo, aspectos epistemológicos, ontológicos, gnosiológicos, teóricos, metodológicos e técnicos da pesquisa científica.

Ao final, os alunos apresentavam os resultados de suas pesquisas para uma banca composta por três professores mestres ou doutores. Participavam da banca, além do professor orientador, um segundo professor da instituição que tinha formação na área do objeto de investigação definido pelo acadêmico em consenso com o professor orientador e um terceiro profissional que era definido pela coordenação do TCC em conjunto com os professores orientadores no semestre. Cabe destacar que por solicitação do colegiado, buscava-se incluir na banca, ao menos, um profissional com formação em Pedagogia, por entender que sua análise seria mais voltada à habilitação do curso. A apresentação oral era pública, incentivando-se acadêmicos de diferentes fases e cursos a assistirem, sendo consideradas como horas de atividades científicas e culturais em que todos os acadêmicos dos cursos de graduação, por legislação, devem participar.

Existiu um incentivo, também, para que os resultados das pesquisas fossem socializados em eventos científicos internos e externos, bem como serem publicados. Além de considerar essa etapa como uma etapa da própria pesquisa em si, compreendemos que ela insere os acadêmicos na cultura científica. Internamente destacavam-se as "Semanas de Educação"; o "Seminário das licenciaturas” e o "Fórum Anual de Iniciação Científica FAIC” como momentos propícios para isso. Externamente, vários acadêmicos, com o apoio de seus professores orientadores, apresentaram suas pesquisas em eventos nacionais e internacionais. Foram publicadas duas edições de revistas internas, única e exclusivamente com as melhores pesquisas de TCC (DINAMYS, 2003 e REVISTA DE DIVULGAÇÃO CULTURAL, 2004). Além disso, o mestrado de educação da instituição disponibiliza a Revista Atos de Pesquisa on line para divulgação dos resultados de pesquisas também de TCCs. 


\section{METODOLOGIA}

A abordagem desta pesquisa é qualitativa e caracteriza-se como "pesquisa documental”, pois as fontes da pesquisa foram os relatórios dos trabalhos de conclusão de curso das acadêmicas do curso de Pedagogia realizados no período de 2001 a 2006. Conforme Gil (2002), na pesquisa documental pode existir dois tipos de documentos: os de primeira mão, ou seja, aqueles que não receberam nenhum tratamento analítico tais como os documentos conservados em órgãos públicos e instituições privadas, e os documentos de segunda mão que de alguma forma já foram analisados tais como: relatórios de pesquisa; relatórios de empresas; tabelas estatísticas e outros. Portanto, os documentos analisados nesta pesquisa correspondem aos de segunda mão.

Segundo o mesmo autor, há vantagens e desvantagens nesse tipo de pesquisa. As vantagens seriam de que os documentos constituem-se fonte rica e estável de dados; baixo custo, pois exige praticamente apenas disponibilidade de tempo do pesquisador; e não exige contato com os sujeitos da pesquisa. Como desvantagens, as críticas mais freqüentes referemse à não representatividade e à subjetividade dos dados.

Também de acordo com André e Lüdke (1986), a análise documental consiste numa técnica valiosa de abordagem de dados qualitativos, complementando as informações obtidas por técnicas, ou desvelando alguns aspectos do tema. Dessa forma, os documentos representam uma fonte estável e rica, podendo-se retirar evidências que fundamentam afirmações do pesquisador. Além disso, a análise documental representa uma fonte natural de informações.

Os dados obtidos foram organizados em um quadro analítico e tabela em planilha no Excel, no qual agrupamos os TCCs em princípio por ano, e depois de maneira geral, destacando a grande área, área e subárea de concentração, vertente teórica e vertente metodológica utilizadas. As áreas e subáreas de conhecimentos atendem as diretrizes do CNPq. Ressaltamos, entretanto, que tivemos dificuldade em caracterizar alguns trabalhos devido à falta de relação direta entre estas áreas e subáreas com o tema investigado. Incluímos os trabalhos que investigaram a educação infantil na subárea de educação pré-escolar; os de formação de professores na subárea de educação permanente e as que focaram à leitura e escrita na subárea de ensino-aprendizagem. 
Apresentamos a seguir a relação da quantidade de trabalhos analisados por ano:

Tabela n.1

\begin{tabular}{|l|c|c|c|c|c|c|c|}
\hline ANO & 2001 & 2002 & 2003 & 2004 & 2005 & 2006 & TOTAL \\
\hline QTDE. & 23 & 132 & 153 & 76 & 52 & 55 & 321 \\
\hline
\end{tabular}

Destacamos ainda que, como o Regulamento do TCC de Pedagogia (FURB, 2001) possibilita a realização da pesquisa em dupla ou individualmente. A maioria dos acadêmicos, 82\%, optou em realizar o trabalho em duplas nos anos analisados, e apenas 18\% individualmente.

Destacamos que essa escolha muitas vezes ocorreu devido à questão financeira, pois no período de 2001 a 2005 os acadêmicos que realizavam o TCC em duplas pagavam à disciplina nove créditos acadêmicos e os que faziam individualmente, pagavam 16 créditos financeiros. Em 2006, esta questão foi modificada e hoje, independente dos alunos fazerem o TCC individualmente ou em duplas, são cobrados nove créditos financeiros de cada acadêmico. Compreendemos que com essa mudança, ocorrerá um maior equilíbrio entre as duas opções propostas no regulamento. As figuras 1 e 2 a seguir já sinalizam que, em 2006, houve uma diminuição no percentual de trabalhos realizados em duplas:

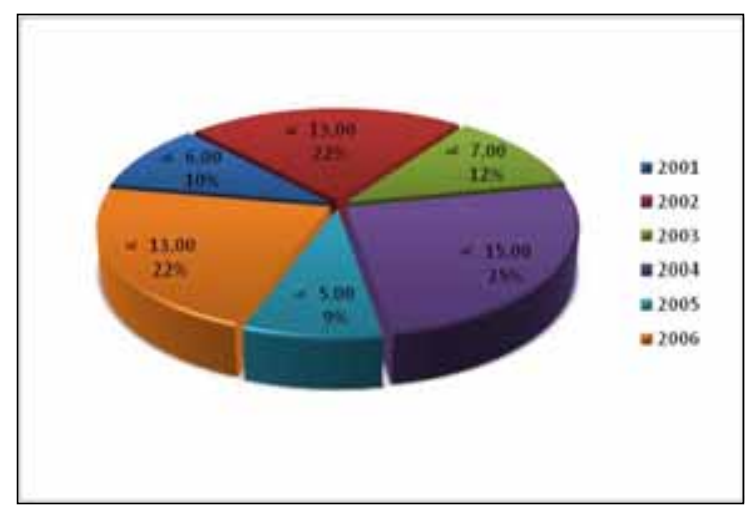

Figura 1 - Apresentação Individual 2001 à 2006

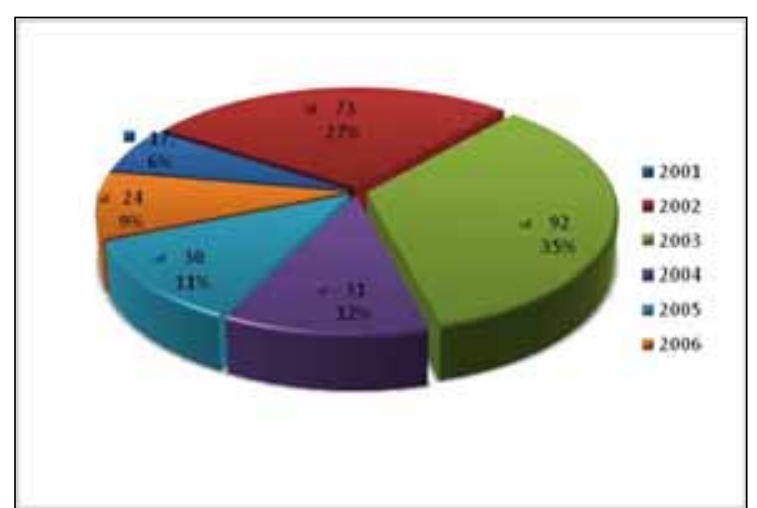

Figura 2 - Apresentação Dupla - 2001 à 2006

As Figuras revelam que em 2006 mais de 30\% dos alunos matriculados na atividade realizaram o TCC individualmente, o que em anos anteriores, nem $10 \%$ dos alunos o faziam. 


\subsection{VERTENTES METODOLÓGICAS DOS TCCS DA PEDAGOGIA}

\subsubsection{Abordagens da pesquisa}

Destacamos que 94\% das pesquisas realizadas delinearam-se na abordagem qualitativas como podemos observar na Figura 3. Compreendemos que essa opção se justifica, pois “a ênfase qualitativa no processo tem sido particularmente útil na investigação educacional” (BOGDAN; BIKLEN, 1994, p. 49).

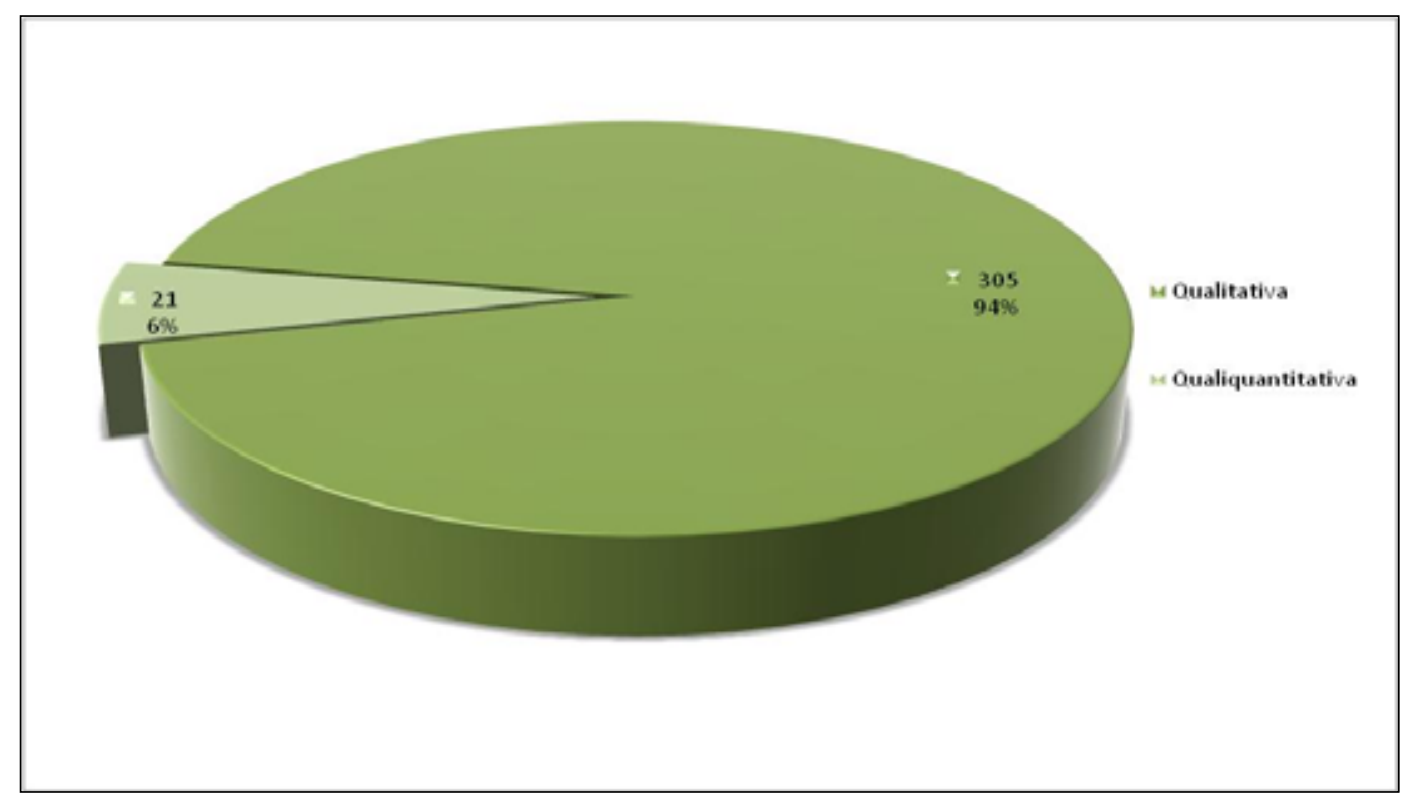

Figura 3 - Abordagens da Pesquisa - 2001 a 2006

Ressaltamos, porém, que não encontramos nenhuma pesquisa de abordagem quantitativa e apenas 6\% foram assumidas pelos pesquisadores como qualiquantitativas. Nas pesquisas qualiquantitativas, ou conforme define Creswell (2003) "método misto”, os acadêmicos relacionaram dados quantitativos e qualitativos na análise para um melhor entendimento do objeto de estudo. Entretanto, nas pesquisas de abordagem qualitativa, percebemos que muitos acadêmicos se utilizaram de dados quantitativos em suas análises. Compreendemos que o cruzamento de dados quantitativos com dados qualitativos feito em muitos trabalhos de TCC merece destaque, pois rompe com uma visão dicotômica entre as abordagens de pesquisa e supera uma visão reducionista de pesquisa. Conforme Luna (1989), a necessária discussão a respeito da adequação de métodos qualitativos em relação 
à captação de determinados fenômenos e processos desenvolveu uma caça às bruxas aos métodos quantitativos, como se não fossem úteis ou mesmo indispensáveis.

\begin{abstract}
"De modo especial, pesquisadores iniciantes sentiram-se atraídos pelas aparentes facilidades do trabalho metodológico com a pesquisa qualitativa, em grande parte devido ao desconhecimento dos recursos oferecidos pelos métodos quantitativos, insubstituíveis em determinados problemas de pesquisa. Hoje já começamos a reconhecer e tentar reparar os males ocasionados por esse desconhecimento procurando oferecer formação sobre técnicas e conceitos próprios da investigação quantitativa” (LUDKE; CRUZ, 2005, p. 81).
\end{abstract}

Precisamos, portanto, superar esta postura reducionista na pesquisa em educação.

\title{
2.2.2 Tipos de pesquisa
}

Cabe destacar, inicialmente, que em alguns trabalhos, não encontramos a definição do tipo de pesquisa. Esta foi analisada e categorizada pelas próprias pesquisadoras a partir da leitura do trabalho. Através da Figura 4, podemos perceber que grande parte das pesquisas foi do tipo exploratória, seguida das pesquisas participante e estudo de caso. Outras modalidades de pesquisas foram utilizadas, porém em número menor como as documentais, etnográficas, bibliográficas e experimentais.

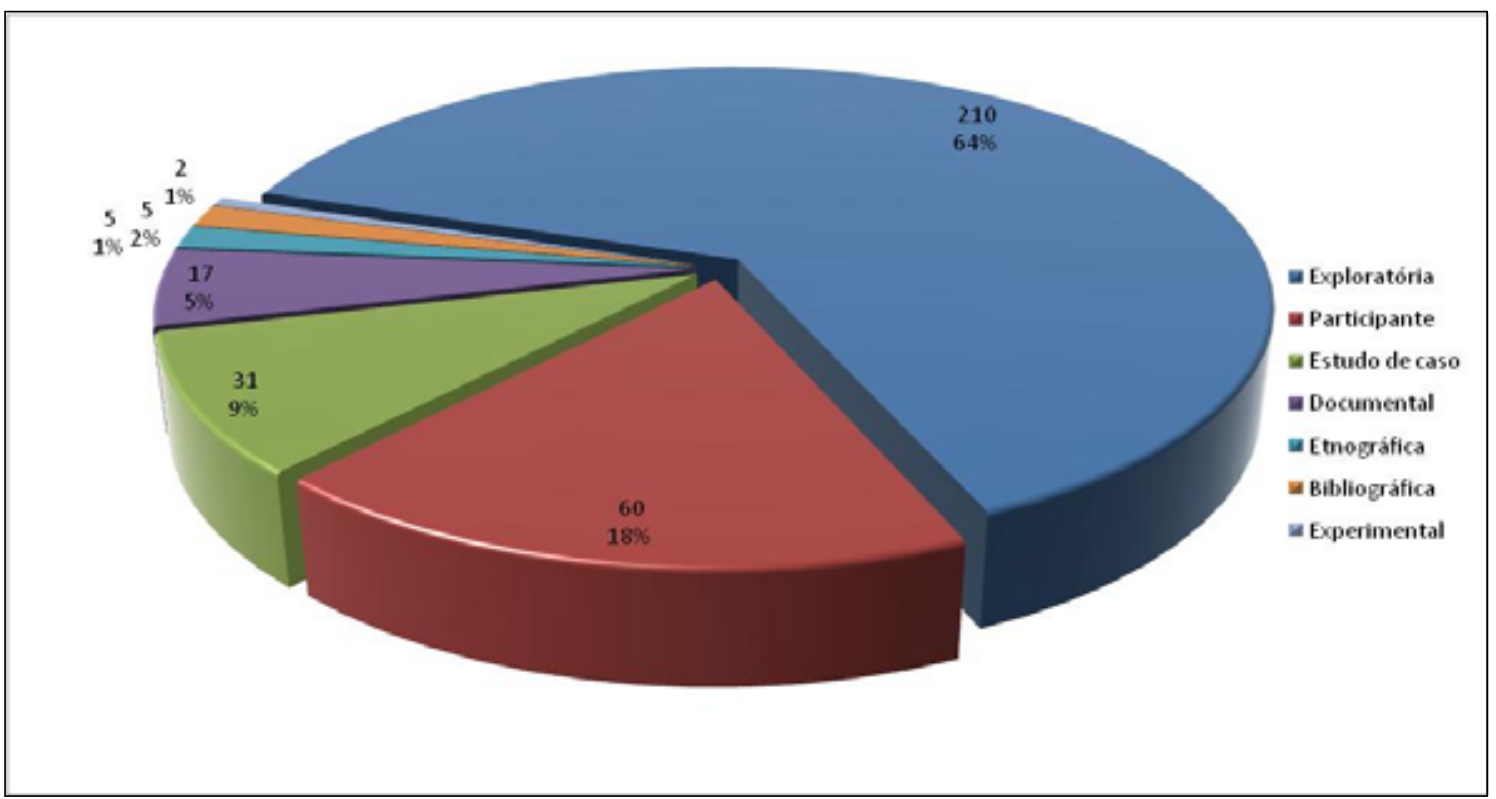

Figura 4 - Tipos de Pesquisa - 2001 a 2006 
Mattar (1993, p.84) destaca que a pesquisa exploratória “é particularmente útil quando se tem uma noção muito vaga do problema de pesquisa". Através do conhecimento mais profundo do assunto em questão, busca-se estabelecer melhor o problema de pesquisa, através da elaboração de questões ou desenvolvimento de hipóteses explicativas para os fatos e fenômenos a serem estudados. Para Cervo e Bervian (2002, p. 49):

\begin{abstract}
“O estudo exploratório [...] é normalmente o passo inicial no processo de pesquisa pela experiência e auxílio que traz na formulação de hipóteses significativas para posteriores pesquisas. Os estudos exploratórios não elaboram hipóteses a serem testadas no trabalho, restringindo-se a definir objetivos e buscar maiores informações sobre determinado assunto de estudo."
\end{abstract}

Frente aos autores acima citados, e considerando-se o TCC como um processo de iniciação à pesquisa, justifica-se a escolha dos acadêmicos por esse tipo de pesquisa.

A pesquisa participante também foi um processo utilizado pelas acadêmicas na realização do TCC. Para Haguete (1987, p.142): “a idéia de participação envolve a presença ativa dos pesquisadores e de certa população em um projeto comum de investigação que é ao mesmo tempo um processo educativo, produzido dentro da ação". Como muitos acadêmicos, ao final da graduação, já atuam em sala de aula é compreensível que alguns queiram desenvolver as pesquisas de forma participativa com seus alunos. $\mathrm{O}$ próprio estágio da Pedagogia, em que predomina projetos de intervenção, desenvolve nos acadêmicos uma postura participativa, voltada à ação/reflexão/transformação da realidade.

Outro tipo de pesquisa muito utilizado pelos acadêmicos foi o estudo de caso. Esse tipo de pesquisa caracteriza-se pela análise intensiva de uma situação particular, pelo seu caráter singular, individualizante, conjetural, aprofundado e detalhado. Yin (1989) justifica a coerência desse tipo de pesquisa quando se busca responder às questões "como" e “porque” por serem questões explicativas, cujo objetivo é “compreender” o fenômeno que não pode ser estudado fora do contexto no qual ocorre. Conforme Chizzotti (2006), é um meio de organizar os dados sociais preservando o caráter unitário do objeto social em estudo. Portanto, esse tipo de pesquisa não visa apontar generalizações, embora compreendamos que um caso pode desvelar realidades universais, porque, guardadas as particularidades, nenhum caso é um fato isolado, e dependente das relações sociais onde ocorre. Percebemos que nos trabalhos utilizados, este tipo de pesquisa predominou, 
principalmente, nos estudos que envolveram pessoas com necessidades especiais, o que requer, normalmente, um estudo mais aprofundado e detalhado.

\subsubsection{Instrumentos de Coleta de dados}

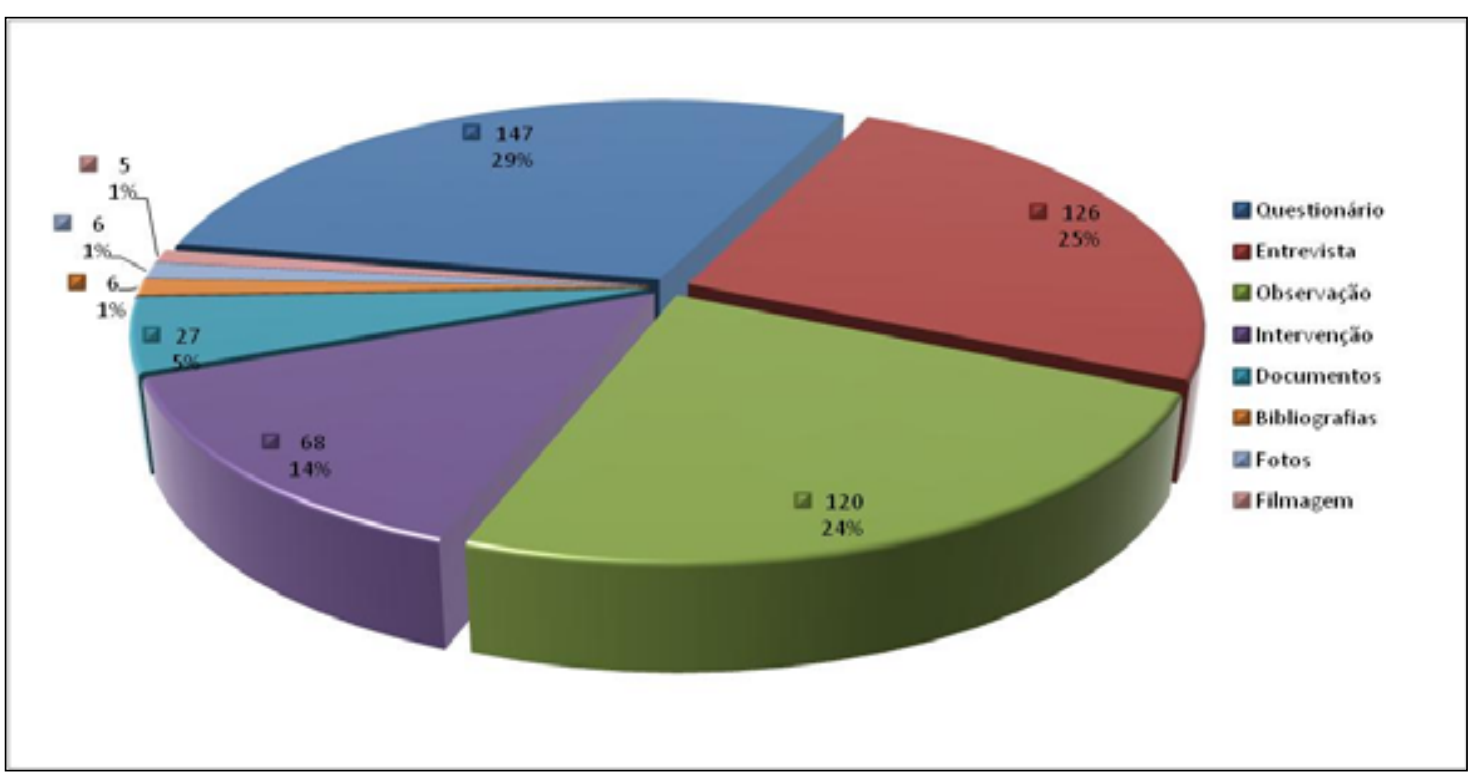

Figura 5 - Instrumento de coleta de dados 2001 a 2006

Nota-se através da Figura 5, que o instrumento de coleta de dados mais utilizado pelos acadêmicos foi o questionário, seguido pela entrevista e pela observação. Merece destaque também a intervenção como uma das alternativas utilizadas pelos acadêmicos na coleta de dados, em se tratando de pesquisas que em sua maioria voltou-se a investigar o contexto pedagógico. Outros instrumentos também foram utilizados, entretanto, em menor escala como a filmagem e a fotografia.

Moreira e Caleffe (2006) apontam que há vantagens e limitações na utilização do uso do questionário em pesquisas voltadas à educação. Os autores referem-se às vantagens como o "uso eficiente do tempo", a preservação da identidade e uma grande possibilidade de retorno dos questionários. “[...] o ponto importante é que o pesquisador normalmente não está presente quando o questionário está sendo preenchido” (MOREIRA; CALEFFE, 2006 p, 95). Desta forma além das vantagens do pesquisador ganhar tempo, o respondente tem mais liberdade para preencher. Das limitações explica-se que os dados coletados pelo uso de questionário tendem a estar descritos ao invés de explicados. Principalmente em questões fechadas, nas quais o respondente preenche os quadros 
formados pelo pesquisador, há questionários que trazem opções de respostas prontas encontrando como respostas apenas sim ou não, em que o pesquisado deve escolher uma delas. As limitações encontram-se ainda na superficialidade das respostas. Sem a presença do pesquisador, não há como questionar o respondente, tentando aprofundar alguma questão, para que esta também se torne mais compreensível pelo respondente evitando equívocos de entendimento.

Ao analisar os TCCS da Pedagogia constatamos que em muitas pesquisas a escolha pelo questionário se deu com uma amostra muito pequena, com poucos respondentes, o que no nosso entender seria mais pertinente o uso da entrevista. Outra limitação descrita pelos autores se trata do tempo para preparar o questionário, apontando que “o tempo gasto na elaboração cuidadosa e no estudo piloto traz muitos benefícios. Um questionário bem elaborado produz dados que não são ambíguos e garantem uma boa taxa de retorno.” (MOREIRA E CALEFFE, 2006 p.104). Gasta-se um bom tempo na elaboração de perguntas pertinentes, condizentes com àquilo que se pretende analisar. Nos trabalhos analisados, constatamos que muitos questionários foram extensos demais, com perguntas redundantes, mal elaboradas e desnecessárias ao problema da pesquisa.

Aproximando-se da porcentagem de questionários utilizados, encontram-se também as entrevistas perfazendo $26 \%$ das pesquisas de TCC. Constatamos que as entrevistas utilizadas foram estruturadas, semi-estruturadas e não-estruturadas. É comum o uso de entrevistas nas Ciências Sociais. Similar ao questionário, a entrevista estruturada segue um modelo com perguntas já elaboradas, diferencia-se do primeiro pela presença do entrevistador. "Ela é mais recomendada em situações em que os participantes têm dificuldades de completar um questionário (crianças muito novas, pessoas quando a língua materna não é aquela usada pelo pesquisador, etc)” (MOREIRA E CALEFFE, 2006, p.167). Em Centros de Educação Infantil, onde a maioria das crianças não domina a escrita, é comum este tipo de entrevista. A entrevista não-estruturada acontece de modo diferente, por não conter perguntas prontas ou fechadas. Mas, a entrevista mais utilizada pelos acadêmicos foi a semi-estruturada, no qual o entrevistador pode aprofundar e incluir novas questões, decorrente da necessidade sentida ao longo da entrevista, não precisando seguir uma seqüência prévia. Cabe ressaltar que, a grande maioria das entrevistas foram audiogravadas e posteriormente transcritas para a análise. 
Para Moreira e Caleffe (2006) existem dois tipos de observação que são mais

utilizados pelos professores em pesquisas: a observação sistemática e a observação participante. Ressaltamos que, nos 26\% da amostra que utilizaram a observação como instrumento de coleta de dados, predominou a observação participante. Para esses autores, na observação sistemática o observador não interfere, nem permanece no local a ser pesquisado, utilizando-se de outros mecanismos para acompanhar a pesquisa, como gravadores ou câmeras de vídeo. Neste caso o pesquisador apenas quer observar o comportamento das pessoas, incluindo suas falas e ações. Este tipo de observação deve acontecer em seguida de outros métodos, algum outro método que possa enfatizar os acontecimentos mais importantes para serem observados. Na observação participante o pesquisador observa a situação como um indivíduo do grupo estudado, inserindo-se em tal realidade. Desta forma o pesquisador pode perceber e registrar os detalhes, principalmente com pesquisas relacionadas à escola, em que os pesquisadores observam as relações de professores e alunos, como descrevem os autores Moreira e Caleffe “[...] As pesquisas nessa área têm como objetivo abrir a "caixa preta” da escola e, por conseguinte da sala de aula, para descobrir os fatores que determinam e influenciam as experiências dos alunos neste contexto” (2006 p.202). Pela baixa porcentagem de câmeras e gravadores que foram utilizados, sendo os gravadores apenas em entrevistas, percebemos que a maioria das observações foi feita pelos próprios acadêmicos no campo, por meio de registros escritos.

Destacamos, também, como ponto alto as pesquisas participantes em que as acadêmicas se utilizaram da intervenção pedagógica como alternativa de coleta de dados. Normalmente foram realizadas por acadêmicas que já atuavam no magistério e se desafiavam em realizar a pesquisa com seus próprios alunos, buscando inovar a sua prática pedagógica.

O que consideramos importante é que alguns acadêmicos utilizaram mais de um instrumento para coletar os dados, buscando envolver seus objetos de investigação sob vários ângulos. Entendemos que isto é algo relevante por se tratar de processos de iniciação à pesquisa, pois conforme destaca Herbert (1990) o uso de diferentes técnicas possibilita a "triangulação", entendida como validação instrumental, uma confrontação dos dados. 


\subsection{VERTENTES TEÓRICAS DOS TCCS DA PEDAGOGIA}

\subsection{1. Áreas e subáreas}

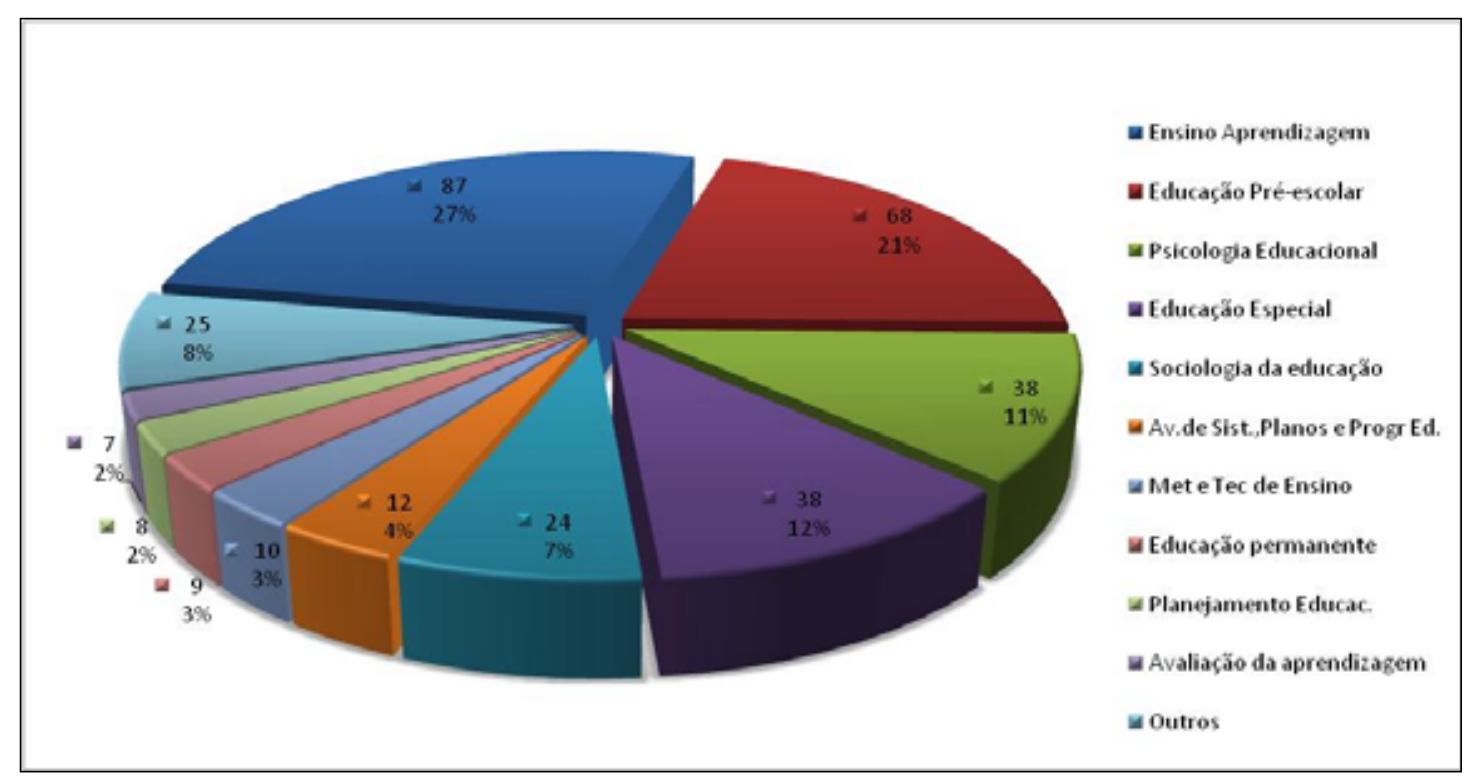

Figura 6 - Subárea do conhecimento - 2001 a 2006

Destacamos que dos 321 trabalhos analisados, todos eles voltaram-se a investigar temáticas relacionadas à grande área Ciências Humanas e a área de Educação. No que se refere às subáreas, percebemos um predomínio em cinco delas: Ensino Aprendizagem, Educação Pré-escolar, Psicologia Educacional, Educação Especial e Sociologia da Educação. Cabe destacar que o curso de Pedagogia não possui, ainda, linhas de pesquisa bem definidas. Entendemos que esta definição é fundamental para qualificarmos cada vez mais as pesquisas neste nível, o que estamos em processo de construção.

Na subárea de ensino-aprendizagem caracterizamos os TCCs que voltaram suas pesquisas para a sala de aula, na atuação do professor, no processo de ensinar e aprender, na leitura, na escrita e na alfabetização. Na subárea de educação pré-escolar contemplamos todas as pesquisas que focaram seus estudos para a educação infantil. A Educação Infantil é uma discussão recente e emergente no contexto educacional o que por si só já justifica sua escolha, além de que a habilitação do curso neste período privilegiou também esta área. Referentes à subárea de Psicologia Educacional encontramos pesquisas 
que se voltaram à investigar a aprendizagem e desenvolvimento da criança, a afetividade, a emoção, os limites, a auto-estima, bem como a relação professor-aluno. Percebemos no gráfico que se destacaram também pesquisas voltadas à Educação Especial. Frente a isto, cabe destacar que, no período analisado, foi ofertado o curso de Pedagogia com esta habilitação. Na subárea de Sociologia, classificamos as pesquisas que se voltaram às influências do contexto social para a aprendizagem da criança, a interação família e escola, o papel dos pais na educação dos filhos e a função social da escola. Outras subáreas tantas foram contempladas, embora com menos freqüência como Avaliação de Sistemas, Planos e Programas Educacionais, Métodos e Técnicas de Ensino, Educação Permanente, Planejamento Educacional e Avaliação da Aprendizagem.

Frente a tal análise constatamos que algumas subáreas importantes, no nosso entender, não estão sendo contempladas pelas pesquisas desenvolvidas nos TCCs na Pedagogia. Merece atenção, por exemplo, a pouca freqüência ou a ausência de pesquisas nas subáreas de Filosofia da Educação; História da Educação; Antropologia Educacional; Tecnologia Educacional; Currículo e Economia da Educação. O desafio está em instigar pesquisas nestas subáreas, bem como analisar as discussões que são realizadas no âmbito curricular do curso de Pedagogia que envolvem tais temáticas.

\subsubsection{Teóricos mais utilizados}

Vários foram os teóricos utilizados nos TCCs da Pedagogia frente à diversidade de temáticas abordadas. Entretanto, elaboramos um gráfico com os autores que alicerçaram mais de vinte trabalhos, como podemos perceber através da Figura 7.

O autor mais utilizado pelos acadêmicos nos TCCs foi Vygotsky, no qual foi declaradamente destacado em 88 dos trabalhos analisados. De renome internacional, por seus estudos relacionados à aprendizagem e ao desenvolvimento, à mediação do conhecimento, à interação social, e por subsidiar as propostas pedagógicas da Rede Estadual e Municipal de Ensino de Blumenau, este autor é muito discutido, nos dias atuais, no âmbito educacional brasileiro e particularmente em nossa região. Contemporâneo de Vygotsky, Piaget realizou estudos relacionados ao desenvolvimento de habilidades cognitivas, estágios de desenvolvimento, construção do conhecimento. A autora Sônia Kramer é escritora de obras relacionadas à educação infantil e a formação de professores 
desta área. Autor de diversos livros, entre eles Pedagogia da Autonomia, livro de cabeceira do professor, Paulo Freire elaborou um plano de alfabetização para adultos, que serviu de base para o conhecido Método Paulo Freire de alfabetização popular. Além disso, foi defensor de uma educação libertadora e emancipatória. Áries foi citado em muitas das pesquisas relacionadas à infância, por suas obras estarem relacionadas á história deste tema, a criança e a sociedade. Nas pesquisas voltadas à afetividade e emoção encontramos o autor Henri Wallon. Ferreiro, pelos seus estudos e pesquisas na área da psicogênese da escrita.

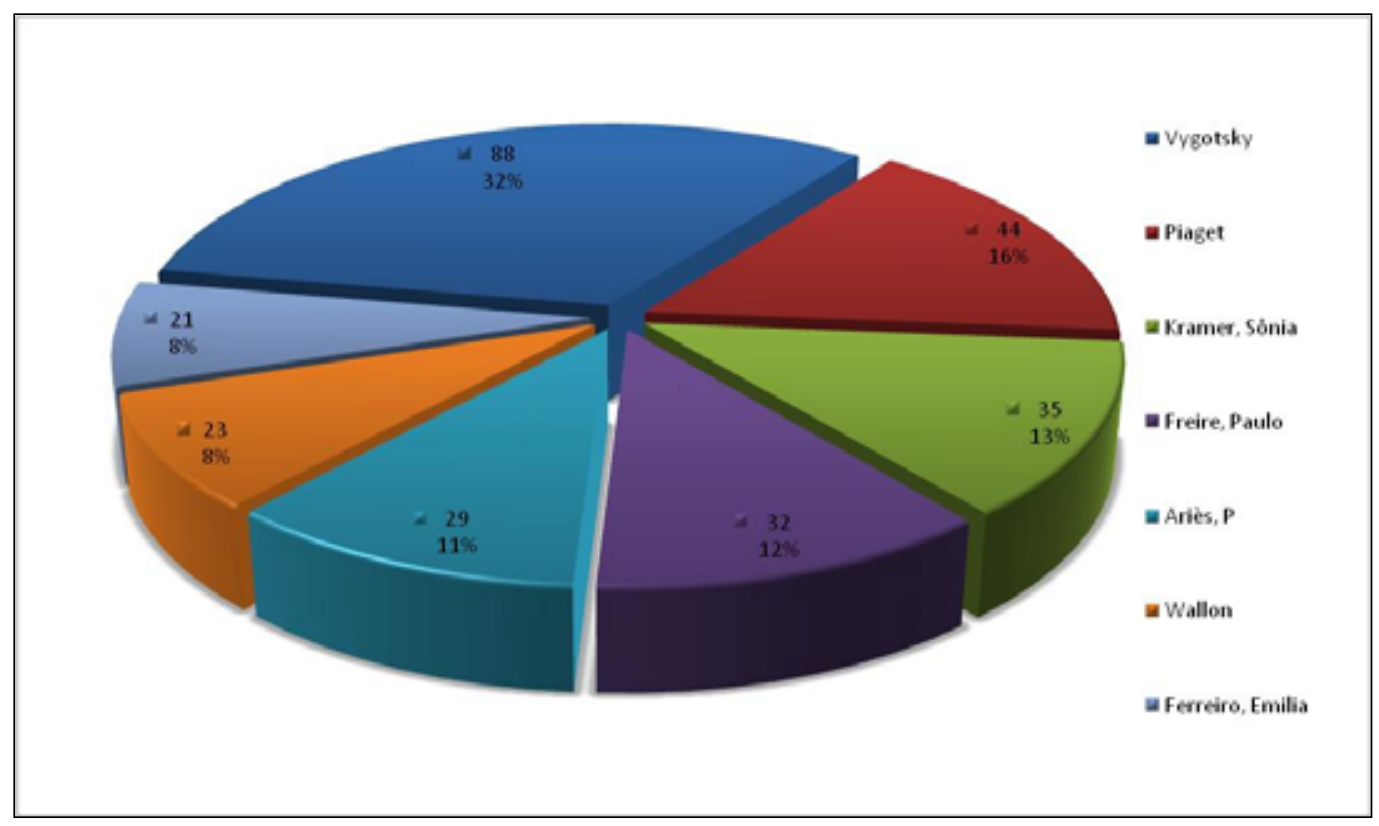

Figura 7 - Vertente Teórica - 2001 a 2006 Utilizados mais de 20 vezes

Constatamos que a escolha destes teóricos pauta-se muitas vezes na seleção de obras já trabalhadas pelos professores durante a graduação, nas diferentes disciplinas que compões a matriz curricular do curso de Pedagogia. Os acadêmicos buscaram aprofundar tais estudos nos trabalhos de conclusão de curso conhecendo a importância do referencial teórico utilizado e buscando respostas, agora, a suas indagações mais particulares. Cabe destacar, entretanto, o cuidado em não banalizar os autores, ficando na superficialidade de suas idéias. Muitas vezes os autores são selecionados pela sua popularidade, e não pela relevância ao objeto de investigação. Entra aqui a importância do professor orientador em auxiliar na definição do suporte teórico da pesquisa. A escolha de teóricos básicos e de obras centrais frente ao objeto em estudo é um processo necessário e fundamental em qualquer pesquisa. Essa escolha deve ser feita com cuidado pelo pesquisador em parceria 
com seu orientador. Geralmente o pesquisador iniciante, pela pouca experiência e falta de leituras, solicita auxilio do seu orientador. "É ele que orienta os alunos na busca de fontes, na escolha de métodos e na seleção de informações relevantes; é ele que os ajuda a sistematizar os dados e avaliar os resultados” (ANDRÉ, 2006, p 223). Entendemos, portanto, que embora no processo seja essencial o envolvimento ativo dos acadêmicos, são imprescindíveis também as orientações e supervisão do professor na escolha do suporte teórico da pesquisa.

\section{CONSIDERAÇÕES FINAIS}

Constatamos que todas as pesquisas focaram para a área da Educação, predominando as subáreas de Ensino Aprendizagem, Educação Pré-escolar, Psicologia Educacional, Educação Especial e Sociologia da Educação. Subáreas estas condizentes com o currículo e as habilitações de formação dos acadêmicos. Entretanto, chamou-nos nossa atenção que em algumas subáreas consideradas importantes não são investigadas pelos acadêmicos. O desafio está em, enquanto professores e orientadores de pesquisa, vislumbrar juntamente com os alunos outras possibilidades de investigação, frente a sua relevância social atual. Compreendemos que sair desta roda de investigação e buscar outros objetos de estudo faz-se importante frente à diversidade, a provisoriedade e a complexidade do processo de ensinar e de aprender.

Quanto à vertente metodológica constatamos que quase todas as pesquisas delinearam-se na abordagem qualitativa. Entretanto, merece destaque a utilização de dados quantitativos na análise, em algumas pesquisas. Os tipos de pesquisa que mais predominaram foram: a pesquisa exploratória, a pesquisa participante e o estudo de caso. Tipos de pesquisa estes mais comuns à área de formação inicial de professores pela natureza do objeto de investigação e por se tratar de pesquisadores iniciantes. Merece destaque também o uso de mais de um instrumento na coleta de dados. Olhar o objeto sob diferentes ângulos, no nosso entender, possibilitou aos acadêmicos compreendê-lo melhor, de maneira mais profunda e precisa. 
Entretanto, Gamboa (1996, p. 7)

\begin{abstract}
“A formação do pesquisador não pode restringir-se ao domínio de algumas técnicas de coleta, registro e tratamento dos dados. As técnicas não são suficientes, nem constituem em si mesmas uma instância autônoma do conhecimento científico. Estas têm valor como parte dos métodos. O método ou caminho do conhecimento é mais amplo e complexo. Por sua vez, um método é uma teoria de ciência em ação que implica critérios de cientificidade, concepções de objeto e de sujeito, maneiras de estabelecer essa relação cognitiva e que necessariamente remetem a teorias de conhecimento e as concepções filosóficas do real. Essas diversas concepções dão suporte às diversas abordagens utilizadas nas construções científicas e na produção de conhecimentos”
\end{abstract}

Este autor afirma, também, que o debate entre abordagens metodológicas deve superar o nível superficial, isto é, resgatar as questões de fundo referentes à gênese do conhecimento, evitando o falso dualismo técnico que limita a atuação do pesquisador a meras questões técnicas. Aqui, trata-se de analisar profundamente quem vai produzir esse conhecimento e a quem esse conhecimento vai servir. Assim, mais importante do que discutir técnicas de pesquisa é explicitar para quê o pesquisador pesquisa: para qual sociedade, que homem, qual a postura do pesquisador frente à problemática social, política e filosófica presente naquele momento. Dessa forma, em qualquer abordagem metodológica escolhida, o pesquisador deixará transparecer sua visão de mundo e suas intenções sobre o objeto pesquisado.

Quanto a vertente teórica constatamos uma íntima relação entre os teóricos selecionados na pesquisa com os autores estudados nas disciplinas do curso. Autores estes muito comuns na área da educação. Entretanto, é preciso tomar cuidado para não banalizálos aprofundando suas idéias e sendo fiel a elas. Analisar o objeto de estudo e vislumbrar outras possibilidades teóricas, às vezes, mais relevantes e condizentes com sua pesquisa, faz-se importante. Cabe ao professor orientador auxiliar os acadêmicos nesta escolha. 


\section{REFERÊNCIAS}

ANDRÉ, M. Ensinar a pesquisar... Como e para quê? In: SILVA, A. M. M. et al. (Orgs.). Educação formal e não formal, processos formativos e saberes pedagógicos: desafios para a inclusão social. Recife: ENDIPE, 2006.

ANDRÉ, M; LUDKE, M. Pesquisa em educação. Abordagens Qualitativas. São Paulo. E.P.U, 1986.

BEILERROT, J. A pesquisa: esboço de uma análise. In: ANDRÉ, M. (Org.). O papel da pesquisa na formação e na prática dos professores. Campinas: Papirus, 2001.

BOGDAN, R; BIKLEN, S. Investigação qualitativa em educação: uma introdução à teoria e aos métodos. Portugal: Porto, 1994

BRASIL. CONSELHO NACIONAL DE EDUCAÇÃO. Proposta de diretrizes para a formação inicial de professores da educação básica em cursos de nível superior. 2001.

. CONSELHO NACIONAL DE EDUCAÇÃO. Diretrizes curriculares nacionais para o curso de pedagogia, 2005.

CERVO, A. L; BERVIAN, P. A. Metodologia Científica. São Paulo: Pearson Prentice Hall, 2002.

CHIZZOTTI, A. A pesquisa em Ciências Humanas e Sociais. São Paulo: Cortez, 2001.

CRESWELL, J.W. Research design: qualitative, quantitative, ande mixed methods appro aches. Thousand Oaks, CA: Sage, 2003.

FERREIRA SOBRINHO, J. W. Metodologia do ensino jurídico e avaliação em Direito. Porto Alegre: Sergio Antonio Fabris Editor, 1997.

FURB. Projeto político pedagógico do curso de pedagogia. Blumenau: FURB, 2004.

Regulamento do trabalho de conclusão de curso de pedagogia. Resolução $n^{0}$ 29, de 27 de junho de 2001.

GAMBOA, S. S. Epistemologia da pesquisa em educação. Campinas: Praxis, 1996.

GIL, A. C. Como elaborar projetos de pesquisa. São Paulo; Atlas. 2002.

HAGUETE, T. M. F. Metodologias qalitativas na sociologia. Petrópolis. Vozes, 1987.

LÜDKE, M. Investigando sobre o professor e a pesquisa. In ROMANOWSKI, J.; MARTINS, P.; JUNQUEIRA, S. (Orgs.). Conhecimento local e conhecimento universal: pesquisa, didática e ação docente. Anais do XII ENDIPE. Curitiba, Champagnat, 2004. 
LÜDKE, M.; CRUZ, G. B. da. Aproximando universidade e escola de educação básica pela pesquisa. São Paulo: Cadernos de Pesquisa, n. 125, v. 35, p. 81-109, 2005.

LUNA, S. V. O falso conflito entre as tendências metodológicas. In: FAZENDA, I. (Org.). Metodologia da pesquisa educacional. São Paulo: Cortez, 1989.

MATTAR, F. Pesquisa de marketing. São Paulo: Atlas, 1993.

MOREIRA, H; CALEFFE, L. Metodologia da pesquisa para o professor pesquisador. Rio de Janeiro: DP\&A, 2006.

YIN, R. K. Case study research: design and methods. USA: Sage Publication, 1989.

MARIA APARECIDA PORTO LUCAS

Bolsista de Iniciação Científica. Acadêmica do curso de Pedagogia da

FURB - SC

E-mail: mariaporto lucas@hotmail.com

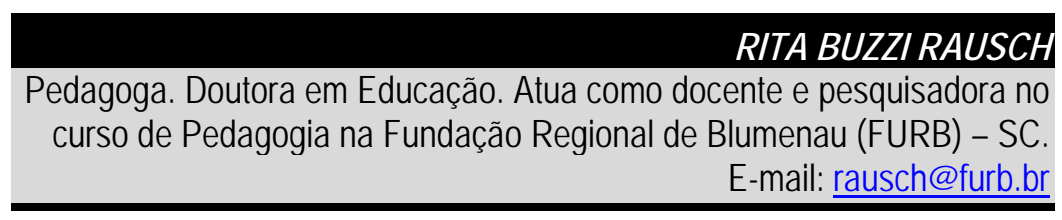

Recebido em: 28/07/2008

Publicado em: 31/01/2009 